Article

\title{
Development of A BIM-Based Maintenance Decision-Making Framework for the Optimization between Energy Efficiency and Investment Costs
}

\author{
Jin-Up Kim ${ }^{1}$, Oussama A. Hadadi ${ }^{2}$, Hyunjoo Kim ${ }^{3, *}$ and Jonghyeob Kim ${ }^{4}$ \\ 1 Department of Residential Construction, Lotte E\&C, Seoul 06527, Korea; kjubee@naver.com \\ 2 Global Urban and Infrastructure Research Center, University of Seoul, Seoul 02504, Korea; \\ had86oa@gmail.com \\ 3 Department of Global Construction, University of Seoul, Seoul 02504, Korea \\ 4 Research and Development Center, PMPgM Co., Ltd., Seoul 02504, Korea; jhkim80@uos.ac.kr \\ * Correspondence: hkim01@uos.ac.kr; Tel.: +82-2-6490-5152
}

Received: 26 June 2018; Accepted: 13 July 2018; Published: 16 July 2018

\begin{abstract}
Eco-friendly materials have been developed recently that have made it possible to significantly reduce the maintenance cost of buildings when they are appropriately used in renovation. Indeed, it became extremely important to consider the eco-friendly energy-saving effects on design alternatives during renovation. The present study proposes a framework for the optimum maintenance decision-making model for considering eco-friendly energy to help people interested in making decisions concerning renovation; it requires that both the environmental friendliness and economic feasibility of the target building be simultaneously considered. Several studies mainly cover the structural aspects for energy improvements based on innovation and technology. However, energy simulation in existing buildings needs some additional consideration regarding the economic analysis of energy savings and the recovery period of construction costs. A case study was conducted as a research method by utilizing the proposed framework, which aims to: (1) make energy simulations with different basic design assumptions; (2) perform the energy simulations through building information modeling (BIM) technology; and (3) analyze the economic feasibility of the alternatives. As a result, an alternative combination that can save the net maximum energy cost during the life cycle period and invest the lowest renovation costs has been recommended. Furthermore, effective guidelines were proposed on which items the building owner values, depending on his economic investment conditions in decision-making regarding the level of design, through a comprehensive review of the energy savings by design variable. It is expected that the research findings will be utilized in the decision-making process and for conducting further relevant research in future.
\end{abstract}

Keywords: renovation; environmental friendliness; energy costs; maintenance; BIM-based; economic analysis; decision-making model

\section{Introduction}

As one of the major economic sectors, buildings consume nearly $32 \%$ of the world's resources, account for around $40 \%$ of the world's energy use and generate up to $30 \%$ of greenhouse gas (GHG) emissions [1]. Buildings in developed countries, which include commercial, residential, and institutional types, consume approximately $35 \%$ to $40 \%$ of the overall estimated energy consumption, including electricity use ranging from $50 \%$ to $65 \%$ [2]. In this respect, during the operational stage of a building's life cycle, a percentage of $80 \%$ to $90 \%$ of energy use was recorded according to United Nations Environment Programme (UNEP). Thus, only $10 \%$ to $20 \%$ of energy is 
consumed throughout raw material processing and extraction, as well as during the manufacturing process for products and construction [3]. Building materials are major components that contribute to the negative effects of the excessive consumption of energy. Therefore, the selection, use, and application of environmentally-friendly materials currently represent an answer to make buildings further environmentally responsible.

Besides, it is generally known that timely and proper maintenance is important to increase the life cycle of buildings [4]. In addition, their environmental friendliness has been taken into consideration even in terms of maintenance due to the recent emergence of eco-friendly buildings. However, many building owners are not seriously concerned about the responsibilities of building maintenance [5]. They usually do not implement environmental friendliness-based maintenance due to the necessary required implication of a complex computer simulation process.

The maintenance work provides an opportunity to improve the energy efficiency of existing buildings during the operational stage [6-8]. However, maintenance during renovation also creates considerable cost and demand for human resources. Thus, in order to satisfy customers, stakeholders in the construction industry should select a building structure while also maintaining a balance for environmental and economic performances. In this context, there is a need for a model that can help the stakeholders make sustainable and eco-friendly decisions, evaluate the effects of energy-efficient alternatives, and quickly select the optimum plan.

\section{Literature Review}

During the life cycle of projects, the building information modeling (BIM) concept covers different aspects and may be used in all stages including design, construction, maintenance, and operation, since it is able to handle several issues relevant to the environment and the building's energy performance, as well as high project costs [9]. However, researchers have had different views on the effectiveness of BIM-based software use in each phase of construction projects. For instance, BIM-related efficiency obtained is higher when implemented throughout initial project stages in comparison with the late phases of a building's life cycle, such as maintenance or operation [10]. Furthermore, the performance of BIM may be affected by various conditions concerning the type of buildings, ownership, and the status referring to existing or new structures [11]. In this regard, Mascio and Wang [12] claimed that BIM is more relevant in the design and management phases and focuses more on different processes of new constructions, while it is less relevant for existing buildings.

According to Gökgür [9], the principal focus of BIM has been moved over time to refurbishment, renovation, and maintenance. The improvement of energy efficiency, environmental degradation reduction, visualization, and creating work collaboration between engineers and consultants as well as various simulations were the main reasons for recommending BIM by specialists in order to enhance the renovation process efficiency. Moreover, amalgamating Information and Communications Technologies (ICT) in renovation, including BIM technology, has been recommended in many research studies, and would significantly improve decision making in the area of cost estimation as well as material arrangement for construction, regardless of some issues in terms of data transmission between software tools and other contract disputes [13].

Concerning the economic analysis in maintenance, Grussing et al. [14] developed a methodology that aims to quickly identify and select multi-dimensional building maintenance, repair, and replacement activities to maximize facility performance and life cycle costs (LCC). This study presented a model framework for selecting optimal work activities considering both conditions and functions as well. Furthermore, the research conducted by Lee et al. [15] has analyzed energy efficiency, $\mathrm{CO}_{2}$ emissions, and LCC to select and analyze the type of external glass that is suitable for high-rise buildings and their various uses. In the same context, a model that aims to predict an optimal renovation time of buildings has been suggested by Cho and Yoon [16] from an economic point of view. Based on the concept that LCC is essential for the construction project-related feasibility evaluation, the effects of the constructed model were verified through an application to an actual renovation project case. In light 
of the above-mentioned reviewed literatures, there is a notable research limitation concerning the economic analysis of energy savings in the renovation process.

In regards to BIM-based energy simulations, Kim et al. [17] proposed a methodology that allows a quick calculation of the estimated energy in the BIM model. This was aimed to create and improve the interoperability between energy simulation engine and BIM software in order to solve problems related to building energy analysis. In addition, the study conducted by Eleftheriadis et al. [18] presented a BIM-based design process in terms of structural engineering and life cycle energy. This process provided an evaluation framework to quantify sustainable and energy-efficient performance standards by using common and new construction technologies, and integrated the intuitive decision-making workflow of accurate engineering practices. Moreover, in order to improve the accuracy of the building energy modeling, Kim et al. [19] suggested a new approach in their study to develop a BIM-based building energy analysis (BEA) system by using an object-based approach in the material properties that was composed of three parts: parsing, material property matching, and writing data input files. It should be noticed that the preceding research mainly emphasized the approach covering material aspects in building energy. They examined the compatibility between BIM and energy analysis software, and investigated the structural aspects in design to improve energy efficiency. However, they did not take into account the overall building maintenance, and do not consider the costs for eco-friendly energy savings.

Several studies have focused on the improvement of building energy performance. For instance, Juan [20] developed an integrated decision-making support system to evaluate existing building conditions and encourage sustainable innovation activities by considering the balance between costs, building quality improvement, and environmental impacts. Nevertheless, this study has shed light on the necessity of presenting optimal results with a view to provide eco-friendly construction regulations and related policies to people in charge, including government officials.

With regard to passive and active application technologies for renovation and major issues, Kim et al. [21] introduced the insulation and the windows as an essential element and effective item, respectively, in addition to the air tightness of shades and windows, which represent the solar radiation control devices. Moreover, Jung [22] performed an energy analysis based on using the analysis model, current legal standards as well as the ones before revision, and passive house standards with respect to structural insulation and highly insulating windows as architectural elements for improving energy performance. Furthermore, Gwon [23] analyzed the annual primary energy requirements with the use of the $\mathrm{ECO}_{2}$ energy analysis program, and by changing the solar radiation transmittance and the heat conduction rate for the top roof and bottom floor of external walls and windows as design change factors.

Consequently, as shown in preceding studies, effective methods for improving the energy performance of existing buildings include insulation performance, the permeability of window glass, window shade installation, and window area ratio. In such analyses, the energy-saving amount was analyzed by either increasing or decreasing the performance standards for each design element compared with the existing model. However, some research that covers the economic analysis has been carried out in this respect. Therefore, this study sought to propose a framework that consider both energy-saving effects and economic efficiency with a focus on the building envelope design elements that have been examined in previous research in order to provide practical help for decision-making processes regarding renovation.

\section{Methodology}

In this study, the proposed framework aiming to derive the optimum planning for maintenance in renovation is clearly outlined in Figure 1.

As previously demonstrated, the methodology used in this study comprises a framework that is largely divided into three major stages. The first stage involves the energy simulation and basic element configuration. This stage is to specify the design factors account for eco-friendly elements 
and define requirements for each design element. The energy simulation is subsequently performed by coding the design factors. The secondly stage involves energy simulation through BIM modeling. This stage includes the construction of a BIM model for the target building in renovation and the analysis of the energy consumption of the building for each design condition by taking into account both climate and local conditions. The third stage analyze the economic feasibility of the alternatives based on the energy simulation results. Hence, it is necessary to designate in this stage the criteria needed to calculate the additional construction costs of the alternatives and the related recovery period, as well as estimate the annual net energy savings.

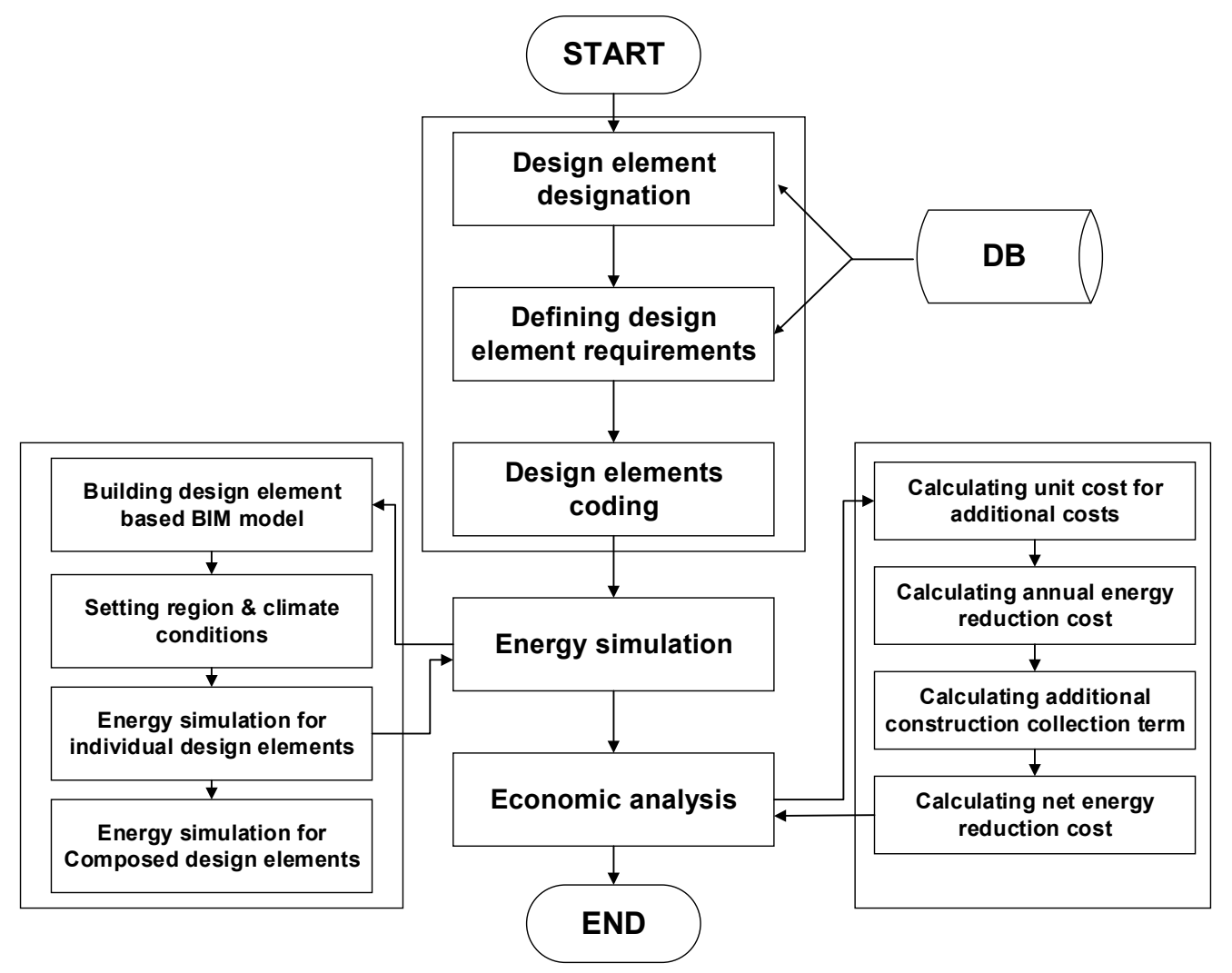

Figure 1. Framework to derive alternatives for maintenance considering eco-friendly energy.

\subsection{Energy Simulation Program and Procedures}

Similar to many other programs used in energy analysis, the Autodesk Green Building Studio is a BIM-based energy analysis software that is widely used in the initial design review stages. This software is able to find out the annual energy consumption of the building, carbon emission quantity, and energy use density per unit area, as some of the results. The Green Building Studio can perform a three-dimensional (3D) modeling of the building design conditions that affect the energy simulation results. It can precisely implement design conditions that include the places with or without roofs, shaded areas, shape, location, and number of shades.

It is commonly known that the improvement of the energy performance of existing buildings highly depends on major factors related to envelope design, which include roofs, external wall and window glass insulation, shade protrusion length, and window area ratio. With respect to these design elements, an energy simulation was performed using the Green Building Studio by setting three levels, namely: the level of regulation at the time of design for the target building, the current regulation level, and the high insulation level for each design variable. Official Korean standards referring to the building location were used as an example in regard to the level of regulations. Thence, Figure 2 
illustrates the design variables combined with three levels of energy performance for the building, as well as the major design factors.

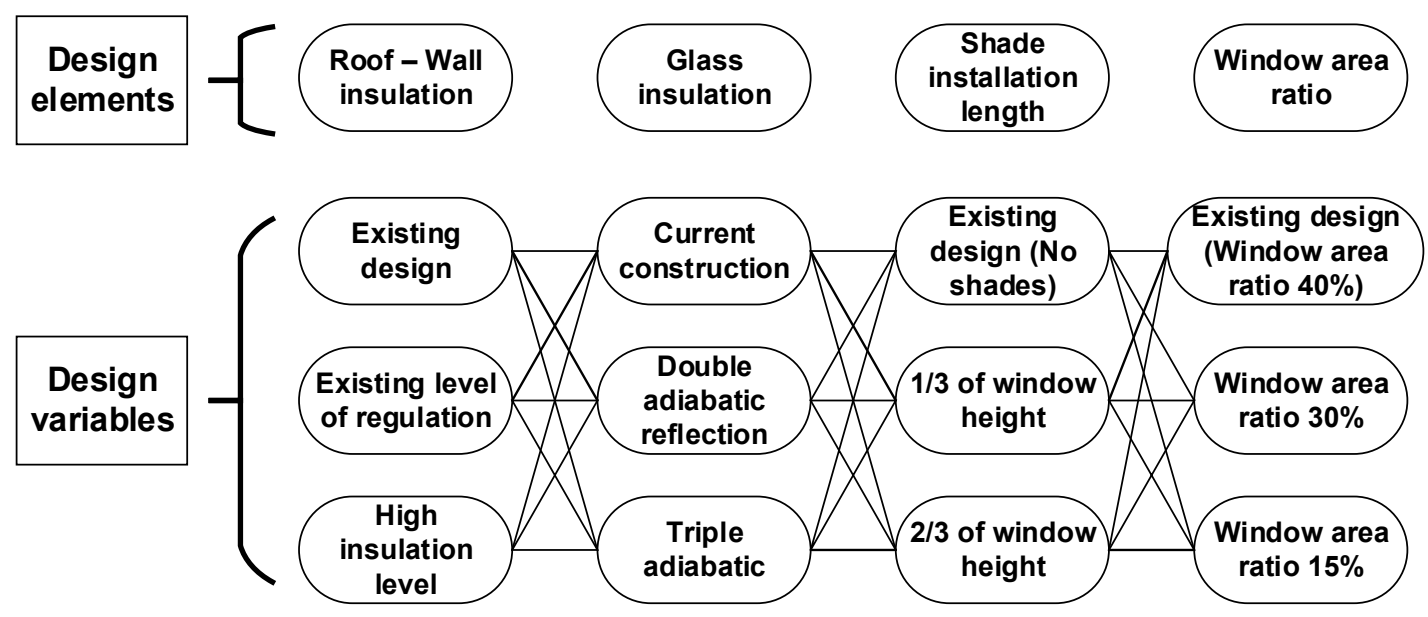

Figure 2. Design variable setting diagram.

Concerning the roof and external wall, insulation standards of $\mathrm{U}=0.41 \mathrm{~W} / \mathrm{m}^{2} \cdot \mathrm{K}$ or $80 \mathrm{~mm}$ and $\mathrm{U}=0.58 \mathrm{~W} / \mathrm{m}^{2} \cdot \mathrm{K}$ or $50 \mathrm{~mm}$ have been used at the design stage for the legal roof and external wall, respectively. Whilst at the energy analysis stage, insulation of $\mathrm{U}=0.45 \mathrm{~W} / \mathrm{m}^{2} \cdot \mathrm{K}$ was applied for the roof, and $\mathrm{U}=0.37 \mathrm{~W} / \mathrm{m}^{2} \cdot \mathrm{K}$ was applied for the external wall. Moreover, in current legal standards related to energy analysis, insulations of $\mathrm{U}=0.17 \mathrm{~W} / \mathrm{m}^{2} \cdot \mathrm{K}$ and $\mathrm{U}=0.24 \mathrm{~W} / \mathrm{m}^{2} \cdot \mathrm{K}$ were used. While for the energy analysis of high insulation levels, $\mathrm{U}=0.11 \mathrm{~W} / \mathrm{m}^{2} \cdot \mathrm{K}$ and $\mathrm{U}=0.17 \mathrm{~W} / \mathrm{m}^{2} \cdot \mathrm{K}$ were applied.

In regard to glass insulation, the legal insulation standards at the time of design require $\mathrm{U}=3.37 \mathrm{~W} / \mathrm{m}^{2} \cdot \mathrm{K}$ or double windows. However, given that there are additional Polyvinyl chloride (PVC) windows installed in individual rooms after the completion of construction, $\mathrm{U}=1.96 \mathrm{~W} / \mathrm{m}^{2} \cdot \mathrm{K}$ (double-pane transparent Low-e glass) was applied in the energy analysis. In addition, the insulation performances of $\mathrm{U}=1.49 \mathrm{~W} / \mathrm{m}^{2} \cdot \mathrm{K}$ (double insulation reflective green Low-e glass) and $\mathrm{U}=1.26 \mathrm{~W} / \mathrm{m}^{2} \cdot \mathrm{K}$ (triple insulation green Low-e glass) were applied in the current legal standards and high insulation standards, respectively.

Since the design criteria for the shade protrusion length and window area ratio are not legally specified, the design variables in this study were set according to the building energy design level. Thus, shade protrusion length was set to no awning, $1 / 3$ of window height, and $2 / 3$ of window height. Furthermore, the target building has a window ratio of $40 \%$, and the window area ratios were set to $30 \%$ and $15 \%$, respectively, in order to adhere to the current legal and high insulation standards. Table 1 shows the coding schemes for managing the above design variables on a systematic basis, and Table 2 indicates the methods for coding combinations concerning each design element.

Table 1. Design variables and coding.

\begin{tabular}{ccccccc}
\hline Division & & $\begin{array}{c}\text { Roof } \\
\text { Insulation }\end{array}$ & $\begin{array}{c}\text { External Wall } \\
\text { Insulation }\end{array}$ & Glass Insulation & Awning Length & $\begin{array}{c}\text { Window } \\
\text { Area Ratio }\end{array}$ \\
\cline { 2 - 6 } & $\mathbf{A}$ & $\mathbf{B}$ & $\mathrm{C}$ & $\mathrm{D}$ & $\mathrm{E}$ \\
\hline Initial Design & 0 & $\mathrm{U}=0.45$ & $\mathrm{U}=0.37$ & $\begin{array}{c}\mathrm{U}=1.96 \\
\text { (double insulation glass) }\end{array}$ & $\mathrm{NA}$ & $40 \%$ \\
\hline $\begin{array}{c}\text { Existing } \\
\text { Regulation Level }\end{array}$ & 1 & $\mathrm{U}=0.17$ & $\mathrm{U}=0.24$ & $\begin{array}{c}\mathrm{U}=1.49 \\
\text { (double insulation } \\
\text { reflecting glass) }\end{array}$ & $\begin{array}{c}1 / 3 \text { of } \\
\text { window height }\end{array}$ & $30 \%$ \\
\hline $\begin{array}{c}\text { High Insulation } \\
\text { Level }\end{array}$ & 2 & $\mathrm{U}=0.11$ & $\mathrm{U}=0.17$ & $\begin{array}{c}\mathrm{U}=0.45 \\
\text { (Triple insulation glass) }\end{array}$ & $\begin{array}{c}2 / 3 \text { of } \\
\text { window height }\end{array}$ & $15 \%$ \\
\hline
\end{tabular}


Table 2. Coding methods for each variable according to the combination of design elements.

\begin{tabular}{ccc}
\hline Coding Contents & $\begin{array}{c}\text { Roof/Exterior Wall/Glass/ } \\
\text { Awning/Window Area Ratio }\end{array}$ & Remarks \\
\hline Coding Model & A(No.)B(No.)C(No.)D(No.)E(No.) & Number in the Bracket = Design Level \\
\hline Example 1 & $\mathrm{A}(0) \mathrm{B}(0) \mathrm{C}(0) \mathrm{D}(0) \mathrm{E}(0)$ & Initial design plan \\
\hline Example 2 & $\mathrm{A}(1) \mathrm{B}(1) \mathrm{C}(1) \mathrm{D}(0) \mathrm{E}(2)$ & $\begin{array}{c}\text { Current regulation level roof and external } \\
\text { wall insulation, double insulation reflecting } \\
\text { glass, no awning, window area ratio 15\% }\end{array}$ \\
\hline Example 3 & $\mathrm{A}(2) \mathrm{B}(2) \mathrm{C}(2) \mathrm{D}(0) \mathrm{E}(1)$ & $\begin{array}{c}\text { High insulation level roof and external wall } \\
\text { insulation, triple insulation glass, no awning, } \\
\text { window area ratio 15\% }\end{array}$ \\
\hline
\end{tabular}

\subsection{Economic Analysis Methods}

Usually, the construction costs invested in renovation are divided into direct and indirect costs. In this study, only the direct construction costs have been calculated to conduct an economic analysis. Furthermore, the additional construction costs considered in this study were particularly the ones geared toward energy efficiency improvement. While dismantling, the re-installation and scaffold installation costs likewise applied in all of the plans were not taken into account. In this regard, the calculation process that was used concerning the additional construction costs was based on using the data related to monthly price, monthly transaction price, and the itemized unit cost of standard unit productivity for project construction. Table 3 further summarizes the preceding details.

Table 3. Basis for the calculation of additional construction costs.

\begin{tabular}{cccc}
\hline \multicolumn{2}{c}{ Division } & Basis & Remarks \\
\hline \multirow{2}{*}{ Direct costs } & Material costs & $\begin{array}{c}\text { Monthly deal data (October, 2016) } \\
\text { Monthly price data (October, 2016) }\end{array}$ & $\begin{array}{c}\text { Korea price research center } \\
\text { Construction association of Korea }\end{array}$ \\
\cline { 2 - 4 } Indirect costs & $\begin{array}{c}\text { Muilding construction standard } \\
\text { Miscellaneous } \\
\text { product estimating guidelines (2016) }\end{array}$ & Estimation research association \\
\hline
\end{tabular}

In fact, the conducted economic analysis considers three principle indicators: namely, a calculation of the annual savings by design variable, a recovery period of additional construction costs, and a consequent savings in net energy. Firstly, the annual energy savings estimated by the Green Building Studio are divided into electric $(\mathrm{kWh})$ and gas $(\mathrm{MJ})$. The total annual energy-saving amount was calculated after multiplying the unit cost of each energy source by the quantified energy savings, as shown in Equation (1).

Annual energy saving amount $(\mathrm{KRW})=$

Annual energy savings $\times$ Unit cost (for each energy source),

Thereafter, the recovery period of additional construction costs was assessed based on the year in which the cumulative amount of annual energy savings is larger compared with the investment cost for renovation by design variables, as indicated in Equation (2). The annual energy-saving amount for each year was calculated by reflecting the annual inflation rate that was estimated to $1.43 \%$.

Recovery period (year) $=$

Year in which the cumulative amount of annual energy savings is larger compared to additional construction costs, 
The net energy savings is the cumulative amount of energy that continues to occur within the life of construction finishing materials after the recovery of additional construction costs, and it was estimated by excluding the additional costs from the total quantified energy savings. The life cycles of finishing vary according to the type of material [24-26]. However, since the purpose of this paper is to propose a framework for the optimum maintenance decision-making model, the average value of 35 years was applied for the finishing materials and related life cycle settings. Therefore, there is a need for future research to apply the various life cycles of finishing to this framework. Equation (3) further describes the preceding details.

Net energy saving amount $(\mathrm{KRW})=$ Total energy savings within the average life of finishing materials - Additional construction costs

Ultimately, based on the calculation methods used above, the recovery period as well as the net energy savings quantified were estimated with the net present value (NPV) method in Equation (4). Table 4 shows the settings for the NPV method.

$$
P V=\sum_{t=1}^{n} \frac{C F}{(1+i)^{t}}
$$

where, $P V=$ present value; $C F=$ cash flow; $i=$ discount rate; $t=$ time (years); $n=$ life cycle of facility (years).

Table 4. Settings for the net present value (NPV) method.

\begin{tabular}{ccc}
\hline Division & Setting Values & Remarks \\
\hline Unit cost & power rates: $120 \mathrm{KRW} / \mathrm{kWh}$, & Expert information \\
Life cycle of finishing & gas rates: $15 \mathrm{KRW} / \mathrm{MJ}$ & The average life of general finishing \\
Inflation rate & 35 years & Average in Korea (2013 2015) \\
Discount rate & $1.43 \%$ & Green Building Studio default setting \\
Depreciation and routine maintenance & $6.1 \%$ & - \\
\hline
\end{tabular}

It should be noticed that the methodology proposed in this chapter for energy simulation procedures and economic analysis methods is transferable to any other building in similar climatic conditions, and can widely be used in different case study approaches. Nevertheless, the author has selected a single case study of an existing building located in the University of Seoul as previously stated, assuming that this would be appropriate to examine and provide the application of the suggested method.

\section{Case Study}

\subsection{Overview of the Target Building}

The target building is an administrative building of a university located in Seoul, Korea with eight storeys, plus one basement level and a floor area of $5287 \mathrm{~m}^{2}$. The building construction was completed in 31 August 1990; it was 26 years old at the time of the present study. A summarized overview and an aerial view for the target building are demonstrated below in Table 5 and Figure 3, respectively.

Table 5. Overview of the target building.

\begin{tabular}{cc}
\hline Division & Contents \\
\hline Types of construction & Office building (University headquarter) \\
Location & Seoul, Korea \\
Floor area/storey & $5287 \mathrm{~m}^{2} /$ B1 $8 \mathrm{~F}$ \\
Structural type & Reinforced Concrete \\
Date of completion of work & August 1990 (26 years since completion) \\
\hline
\end{tabular}




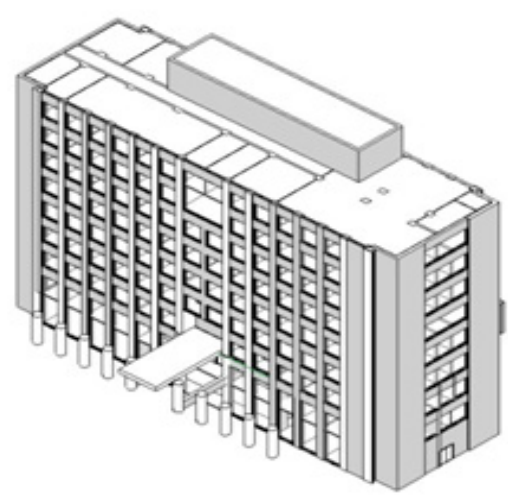

(a)

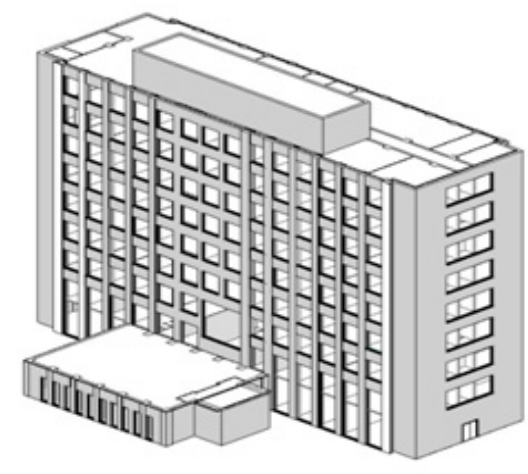

(b)

Figure 3. Design variable setting diagram: (a) front view; (b) rear view.

The design conditions and the building operation for energy simulation were established by utilizing the climate data and the default value of the office building provided by the Green Building Studio. The results have been confirmed through the conducted field survey, in addition to the design drawings of the target building. A summarized comprehensive status concerning energy simulation setting conditions is indicated in Table 6.

Table 6. Energy simulation setting conditions.

\begin{tabular}{|c|c|c|}
\hline \multicolumn{2}{|c|}{ Division } & Contents \\
\hline \multirow{3}{*}{ General term } & Types of construction & Office \\
\hline & Location & Seoul, Korea \\
\hline & Storey & B1 8F, Floor space: $5287 \mathrm{~m}^{2}$ \\
\hline \multirow[b]{2}{*}{ Service in construction } & Heating & Central heating: radiator \\
\hline & Others & $\begin{array}{l}\text { Number of people: } 201 \\
\text { light: } 9.69 \mathrm{~W} / \mathrm{m}^{2} \\
\text { Electric heat: } 13.72 \mathrm{~W} / \mathrm{m}^{2}\end{array}$ \\
\hline \multirow{5}{*}{ Service in construction } & Roof & $\begin{array}{l}\qquad \mathrm{U}=0.45 \mathrm{~W} / \mathrm{m}^{2} \cdot \mathrm{K} \\
\text { (Legal standard in } 1987: \mathrm{U}=0.41 \mathrm{~W} / \mathrm{m}^{2} \cdot \mathrm{K} \\
\text { or } 80-\mathrm{mm} \text { insulation) }\end{array}$ \\
\hline & External wall & $\begin{array}{c}\mathrm{U}=0.37 \mathrm{~W} / \mathrm{m}^{2} \cdot \mathrm{K} \\
\text { (Legal standard in } 1987: \mathrm{U}=0.58 \mathrm{~W} / \mathrm{m}^{2} \cdot \mathrm{K} \\
\text { or } 50-\mathrm{mm} \text { insulation) }\end{array}$ \\
\hline & Exterior window & $\begin{array}{l}\mathrm{U}=1.96 \mathrm{~W} / \mathrm{m}^{2} \cdot \mathrm{K} \\
\text { (Legal standard in } 1987: \mathrm{U}=3.37 \mathrm{~W} / \mathrm{m}^{2} \cdot \mathrm{K} \\
\text { or double window) }\end{array}$ \\
\hline & Awning & - \\
\hline & Window area ratio & $40 \%$ \\
\hline
\end{tabular}

\subsection{Energy Performance Simulation Considering Design Elements}

The design variables set in this study are divided into individual elements, including roofs and external insulation, window glass insulation, shade installation length, and window area ratio changes, as well as composite elements formed by the combination of these individual elements. The simulation of individual elements was firstly performed in order to confirm the correlation between them and the changes of cooling and heating-related energy. 


\subsubsection{Simulation of Individual Design Elements}

The simulation results of individual design elements are described below.

(1) Roof and external wall insulation changes

The results of the energy simulation from improving the heat transmittance value to current regulation levels compared to its value in the original design, with respect to roof and external wall insulation, showed that the energy consumption of gas has reduced by $8.8 \%$ and electricity has reduced by $0.9 \%$. In addition, the simulation results obtained from improving the heat transmittance to high insulation levels revealed an estimated reduction of $10.8 \%$ and $0.9 \%$ in energy consumption for gas and electricity, respectively.

(2) Window glass insulation changes

Otherwise, the energy simulation results found that following the improvement of the heat transmittance value to the level of current regulations (double insulation reflective glass) compared to the value of the original design, with respect to the window glass installed on external walls, estimated energy use reduction was $6.2 \%$ for gas and $8.5 \%$ for electricity. In this regard, the electric energy-saving ratio was higher compared to the results mentioned above when the levels of the roof and external wall insulations were improved. This was due to blocking the indoor solar radiation gains in summer through the use of reflective glass, rather than improving the glass-related heat transmittance. In addition, the results showed that after improving the heat transmittance to the level of high insulation (triple insulation glass), energy consumption decreased by $11.9 \%$ and $4.3 \%$ for gas and electricity, respectively.

\section{(3) Shade protrusion length changes}

In regard to the indoor solar radiation blocking through the change of shade protrusion length, an energy simulation was performed based on two different cases. The first refers to the original design without shades, while in the second case, shades were installed at $1 / 3$ and $2 / 3$ of the vertical lengths of windows. Therefore, the energy consumption has reduced by $4.6 \%$ and $3.4 \%$ for gas and electricity, respectively, in case of being shaded with $1 / 3$ of the vertical length of window. Furthermore, a reduction of energy consumption that was estimated at $6.2 \%$ for gas and $6 \%$ for electricity has been evidenced in cases where the areas were shaded to $2 / 3$ of the vertical length of windows. Thus, it has been determined that blocking the direct rays of the sun through the installation of shades enables significantly reducing the energy consumption during summer.

(4) Window area ratio changes

The energy simulation has been done with respect to cases in which the window area ratios represented $30 \%$ and $15 \%$, compared to the original ratio of $40 \%$. In the first case, the energy use reduction was estimated at $10 \%$ for gas and $3.4 \%$ for electricity. When the window area ratio was $15 \%$, these percentages changed to $23.7 \%$ and $7.7 \%$, respectively. The above energy savings of gas were deemed the highest among the individual elements due to improving the building insulation performance and became more effective compared to the one for window glass, and the performance increases if the window area ratio is reduced. Concerning electricity use, the reduction of cooling energy consumption during summer occurred with the improved insulation performance of the building envelope following the reduction in the window area ratio.

(5) Sub-conclusion

According to all the preceding simulation results, which are summarized in Figure 4, both gas and electric energy consumption were remarkably decreased when changing the window area ratio to $15 \%$ and using double insulation reflective glass, respectively. Moreover, the consumption of gas energy has a direct relationship with the insulation performance of the building envelope. Nevertheless, 
electric energy use has significantly changed depending on the degree of blocking the solar radiation entering the room, instead of improving the insulation performance.

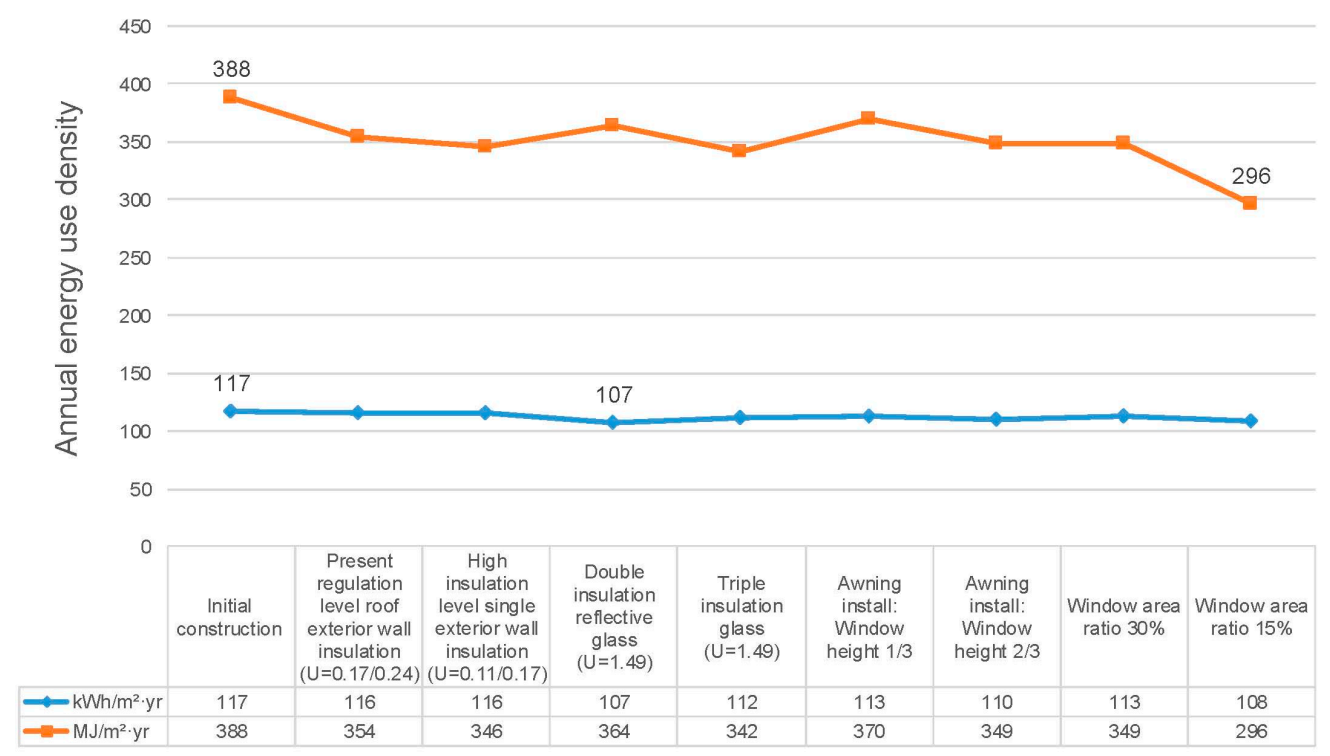

Figure 4. Density of annual energy use by design variable of individual elements.

\subsubsection{Simulation of the Composite Elements}

In fact, the simulation of all of the design variables for the target building was performed, and the analysis was conducted by dividing the density of energy use per unit area into the density of energy consumption for electricity and gas, as well as the total amount of energy used. The figures below refer to the overall status concerning the aforementioned analysis.

As shown in Figures 5-7, the cases A2, B2, C2, D2, and E2 refer to high insulation, level roof and external wall insulation, triple insulation glass, a shade protrusion length of $2 / 3$ of the window related vertical length, and a window area ratio of $15 \%$, respectively. All of the design elements for energy savings are reflected to the maximum; the highest total energy reduction is equivalent to an energy-saving ratio of $23.6 \%$. Concerning the above design variables, it should be noticed that the energy consumption density remains the same even if the shade protrusion length changes in spite of other conditions. This was due to a little change in the total energy-use density following the insignificant changes in electricity and gas consumption. It was understood that the annual total energy was reduced by $11.9 \%$ according to the results of the energy simulation with the current legal standards, which are A1, B1, C1, D0, and E0.

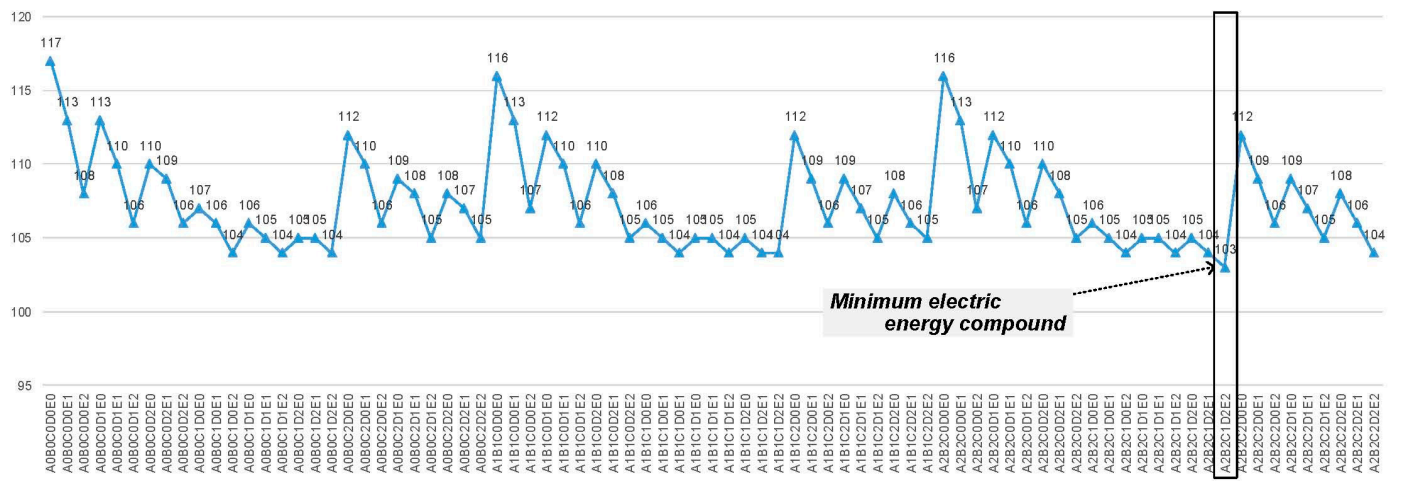

Figure 5. Density of annual electric energy use by design variable. 


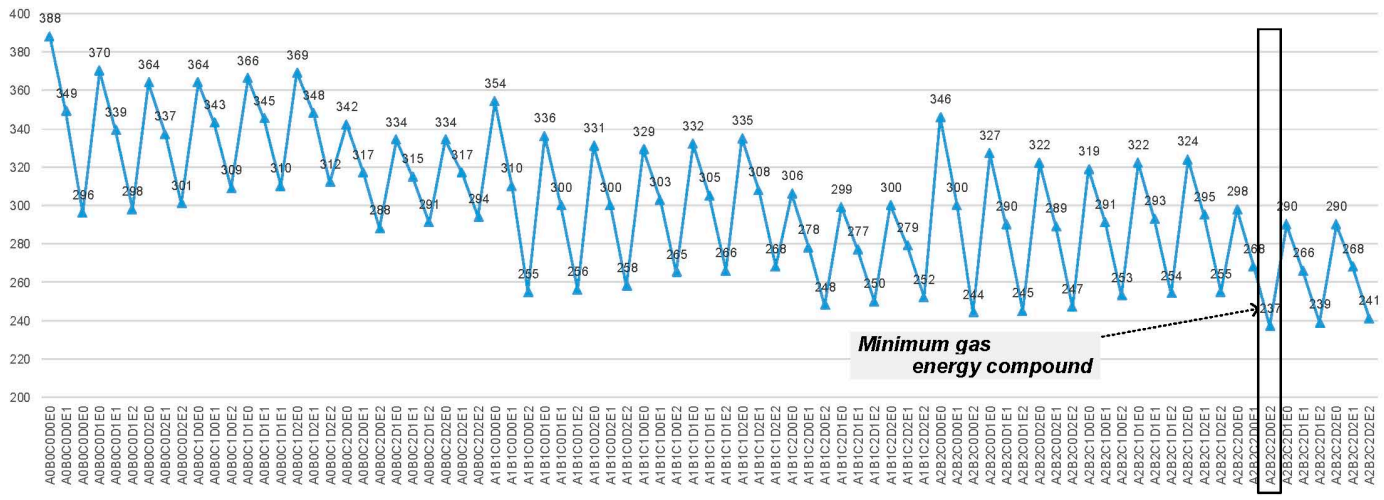

Figure 6. Density of annual gas energy use by design variable.

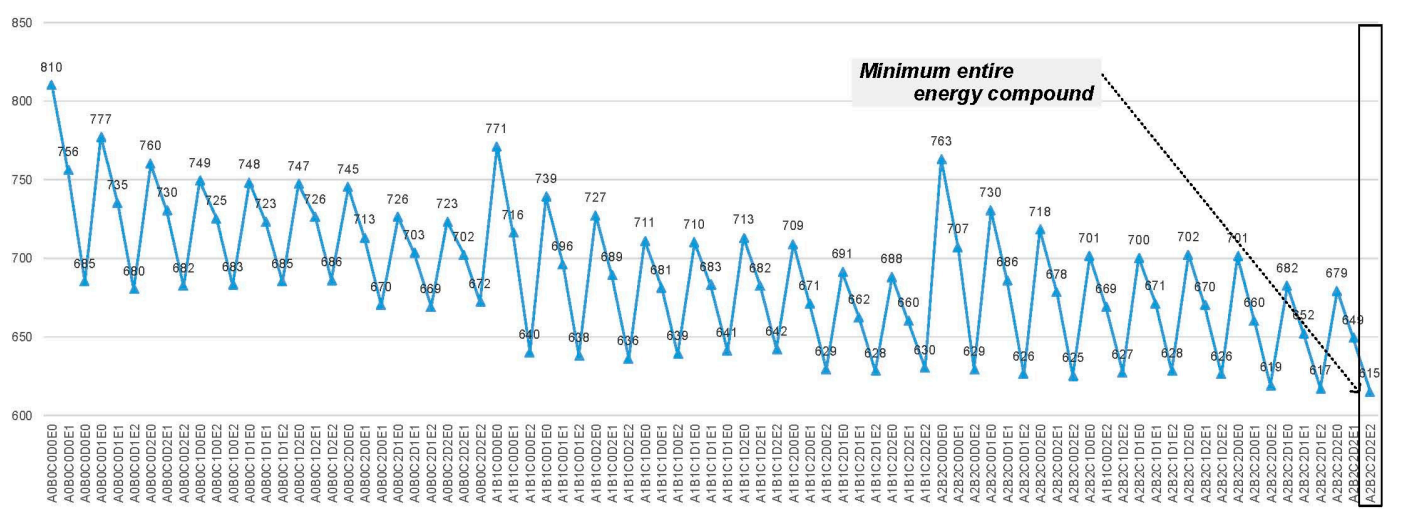

Figure 7. Density of annual total energy use by design variable.

The cases of A2, B2, C1, D2, and E2 referring to high insulation-level roof and external wall insulation, double insulation reflective glass, a shade protrusion length of $2 / 3$ of the vertical length of window, and a window area ratio of $15 \%$, respectively have exhibited the greatest electric energy reduction effects, with an energy saving ratio of $12 \%$. In this case, the electric energy-saving rate was nearly $0.8 \%$ higher compared to the case when using triple insulation glass, which indicates that double reflective glass is actually more advantageous than triple glass in terms of reducing electric energy consumption. The results of the energy simulation according to the current legal standards A1, B1, C1, D0, and E0 showed a reduction of annual electric energy by $9.4 \%$.

On the other hand, the gas energy-saving effect was the highest in the case of A2, B2, C2, D0, and E2, which refer to high insulation-level roof, external wall insulation, triple insulation glass, the absence of shade installation, and a shade area ratio of $15 \%$, respectively with an energy-saving ratio of $38.9 \%$. The use of glass with a high insulation performance and the installation of shades with a low window area ratio have contributed to an increase in heating-related energy consumption. Usually, the latter increases as well in winter if the indoor influx of sunlight is excessively blocked due to multiple factors. Therefore, the energy simulation results adhering to current legal standards A1, B1, $\mathrm{C} 1, \mathrm{D} 0$, and E0 demonstrate a reduction of $15.2 \%$ in annual gas energy.

\subsection{Economic Analysis}

The economic analysis conducted for the design variables was previously stated in Section 2 of Chapter 3, where both the analysis method and calculation of additional construction costs have been described. Moreover, the overall status is shown in Table 7. 
Table 7. Overall status of annual energy savings by design variable (partial example).

\begin{tabular}{|c|c|c|c|c|c|c|c|}
\hline \multirow{2}{*}{ Division } & \multicolumn{3}{|c|}{ Annual Reduction Costs (KRW) } & \multirow{2}{*}{$\begin{array}{c}\text { Finishing Materials } \\
\text { Energy Life Reduction } \\
\text { Costs (KRW) } \\
\begin{array}{c}\text { Average Value for } \\
35 \text { Years }\end{array}\end{array}$} & \multirow{2}{*}{$\begin{array}{l}\text { Additional } \\
\text { Construction } \\
\text { Costs (KRW) }\end{array}$} & \multirow{2}{*}{$\begin{array}{c}\text { Collect } \\
\text { Year }\end{array}$} & \multirow{2}{*}{$\begin{array}{c}\text { Net Reduction Cost after } \\
\text { Collecting Additional } \\
\text { Construction Costs } \\
\text { (KRW) }\end{array}$} \\
\hline & $\begin{array}{l}\text { Electric } \\
\text { Charges }\end{array}$ & $\begin{array}{c}\text { Gas } \\
\text { Charges }\end{array}$ & Total & & & & \\
\hline A0 B0 C0 D0 E0 & - & - & - & - & - & - & - \\
\hline A0 B0 C0 D0 E1 & $2,372,160$ & $3,116,235$ & $5,488,395$ & $247,057,930$ & $81,732,199$ & 14 & $165,325,731$ \\
\hline A0 B0 C0 D0 E2 & $5,782,440$ & $7,291,785$ & $13,074,225$ & $588,531,070$ & $156,477,199$ & 12 & $432,053,871$ \\
\hline A0 B0 C0 D1 E0 & $2,621,760$ & $1,465,995$ & $4,087,755$ & $184,008,670$ & $35,069,821$ & 9 & $148,938,850$ \\
\hline A0 B0 C0 D1 E1 & $4,239,240$ & $3,950,265$ & $8,189,505$ & $368,647,330$ & $116,802,019$ & 14 & $251,845,311$ \\
\hline A0 B0 C0 D1 E2 & $6,534,480$ & $7,159,800$ & $13,694,280$ & $616,442,600$ & $191,547,019$ & 13 & $424,895,581$ \\
\hline A0 B0 C0 D2 E0 & $3,999,000$ & $1,922,370$ & $5,921,370$ & $266,548,130$ & $70,139,641$ & 12 & $196,408,489$ \\
\hline A0 B0 C0 D2 E1 & $5,171,160$ & $4,049,040$ & $9,220,200$ & $415,043,660$ & $151,871,840$ & 15 & $263,171,820$ \\
\hline A0 B0 C0 D2 E2 & $6,908,160$ & $6,956,070$ & $13,864,230$ & $624,092,830$ & $226,616,840$ & 15 & $397,475,990$ \\
\hline A0 B0 C1 D0 E0 & $6,363,360$ & $1,916,175$ & $8,279,535$ & $372,699,990$ & $81,688,847$ & 10 & $291,011,143$ \\
\hline A0 B0 C1 D0 E1 & $6,916,080$ & $3,590,610$ & $10,506,690$ & $472,954,490$ & $285,388,855$ & 24 & $187,565,635$ \\
\hline A0 B0 C1 D0 E2 & $7,758,480$ & $6,291,765$ & $14,050,245$ & $632,466,220$ & $311,000,229$ & 20 & $321,465,991$ \\
\hline A0 B0 C1 D1 E0 & $6,890,160$ & $1,738,470$ & $8,628,630$ & $388,414,370$ & $116,758,668$ & 13 & $271,655,703$ \\
\hline A0 B0 C1 D1 E1 & $7,303,440$ & $3,409,215$ & $10,712,655$ & $482,225,930$ & $320,458,675$ & 26 & $161,767,255$ \\
\hline A0 B0 C1 D1 E2 & $7,938,720$ & $6,188,865$ & $14,127,585$ & $635,947,650$ & $346,070,049$ & 22 & $289,877,601$ \\
\hline A0 B0 C1 D2 E0 & $7,153,320$ & $1,501,110$ & $8,654,430$ & $389,575,740$ & $151,828,488$ & 16 & $237,747,252$ \\
\hline A0 B0 C1 D2 E1 & $7,493,640$ & $3,234,900$ & $10,728,540$ & $482,940,980$ & $355,528,496$ & 28 & $127,412,484$ \\
\hline A0 B0 C1 D2 E2 & $8,024,400$ & $6,092,430$ & $14,116,830$ & $635,463,520$ & $381,139,870$ & 23 & $254,323,650$ \\
\hline
\end{tabular}

When shade protrusion length represents $1 / 3$ of the window vertical length, as demonstrated in Table 7 and Figures 8 and 9, A0, B0, C0, D1, and E0 have exhibited the fastest recovery of all of the additional construction costs, which requires nine years. This case refers to design variables in which the total energy saving was estimated to $4 \%$, which was deemed the lowest. With regard to triple insulation glass, A0, B0, C2, D0, and E0 showed the slowest recovery of additional costs, requiring 43 years. The reason is that the triple glass thickness $(43 \mathrm{~mm})$ does not allow the use of existing window frames, and lead to excessive re-construction costs after dismantling. According to the results for current legal standards A1, B1, C1, D0, and E0, 10 years were required for recovery. Meanwhile, for the design variables with the most significant energy savings, the recovery period needed was estimated to 23 years in regards to A2, B2, C2, D0, and E2.

Concerning the net energy savings within the average life of finishing materials after the recovery of additional construction costs, 57 design variables were analyzed without considering five variables in which the additional construction costs cannot be covered, as well as 18 alternatives where only the window area ratio specifically changed. The findings indicate that the variables that have the highest net energy savings were A1, B1, C1, D0, and E2, representing the roof at the level of current regulations, external wall insulation, double insulation reflective glass, the absence of shades, and a window area ratio of $15 \%$, respectively. Therefore, the saving amount was estimated to $405,383,157 \mathrm{KRW}$ (equivalent to $76,680 \mathrm{KRW} / \mathrm{m}^{2}$ ), and the recovery period was 20 years.

Otherwise, for design variables i.e., $\mathrm{A} 0, \mathrm{~B} 0, \mathrm{C} 0, \mathrm{D} 1$, and $\mathrm{E} 0$ with a recovery period of nine years, the related saving amount was $148,938,850 \mathrm{KRW}$ (equivalent to $28,170 \mathrm{KRW} / \mathrm{m}^{2}$ ). Regardless of the short recovery time needed, the annual energy saving rate was low in this case (4\%), resulting in a low amount of net energy saving. On the other hand, based on current legal standards for A1, B1, C1, D0, and E0, the energy saved and quantified, as well as the period required for recovery, were estimated to $340,960,739 \mathrm{KRW}\left(64,490 \mathrm{KRW} / \mathrm{m}^{2}\right)$ and 14 years, respectively. Meanwhile, these estimations changed to $356,079,228 \mathrm{KRW}\left(67,350 \mathrm{KRW} / \mathrm{m}^{2}\right)$ and 23 years for variables with the largest amount of total energy savings i.e., A2, B2, C2, D0, and E2. The summary of these findings is shown in Table 8. 


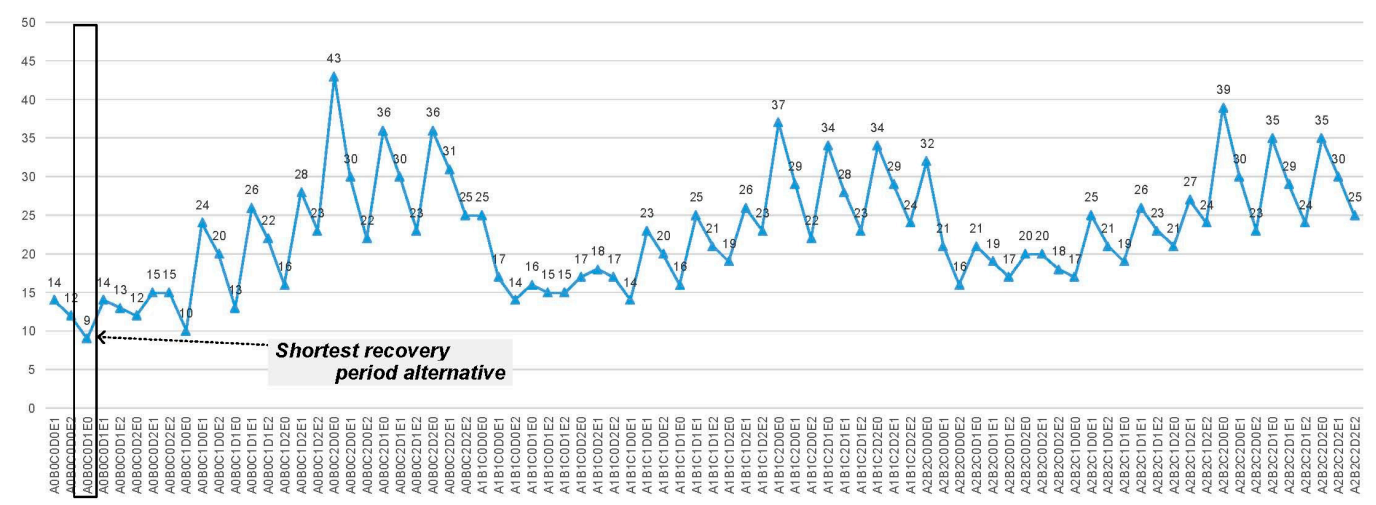

Figure 8. Recovery year of additional construction costs by design variable (year).

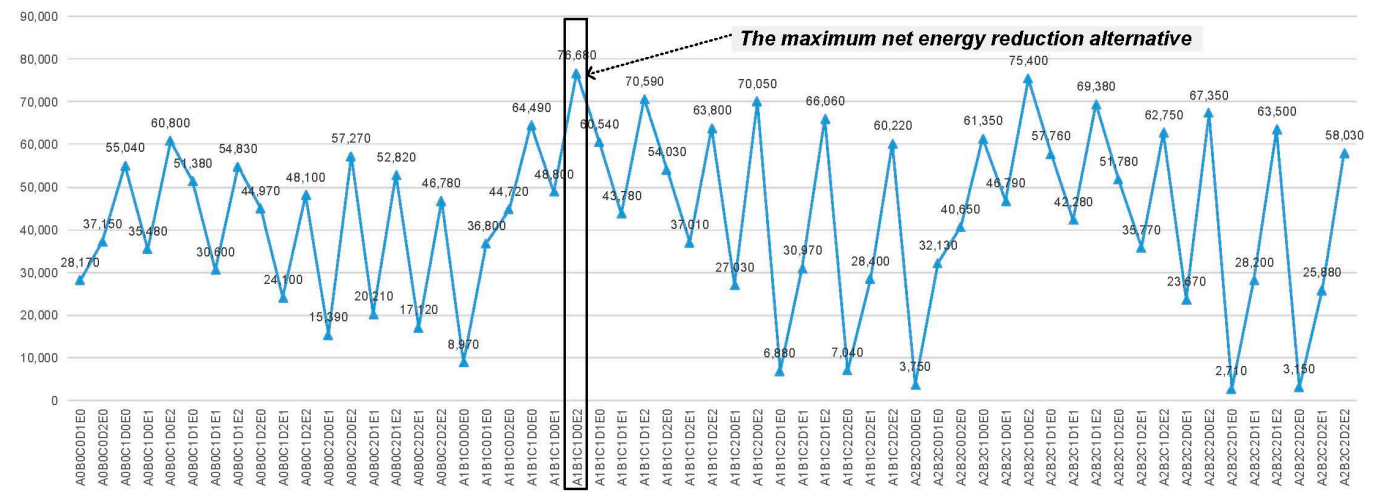

Figure 9. Net energy saving amount within average life of finishing materials after the recovery of additional construction costs $\left(\mathrm{KRW} / \mathrm{m}^{2}\right)$ variable (year).

Table 8. Annual energy saving and economic analysis status for each design variable.

\begin{tabular}{ccccccc}
\hline \multirow{2}{*}{ Division } & \multicolumn{2}{c}{ Annual Energy Reduction Amount } & \multicolumn{2}{c}{ Savings (KRW) } \\
\cline { 2 - 6 } & Electricity (kWh) & Gas (MJ) & Total (MJ) & $\%$ & Annual & Finishing Material Life \\
\hline A0 B0 C0 D1 E0 & 21,848 & 97,733 & 174,471 & $4.10 \%$ & 773 & 34,804 \\
A1 B1 C1 D0 E2 & 67,256 & 652,540 & 893,503 & $20.90 \%$ & 3378 & 152,054 \\
A1 B1 C1 D0 E0 & 55,302 & 313,152 & 507,552 & $11.90 \%$ & 2144 & 96,496 \\
A2 B2 C2 D0 E2 & 58,242 & 800,377 & $1,009,817$ & $23.60 \%$ & 3593 & 161,725 \\
A2 B2 C2 D2 E0 & 48,182 & 518,805 & 687,310 & $16.10 \%$ & 2566 & 115,486 \\
A2 B2 C2 D2 E2 & 64,748 & 779,267 & $1,009,817$ & $23.60 \%$ & 3680 & 165,676 \\
\hline
\end{tabular}

According to Table 8, the use of maximum costs as described by A2, B2, C2, D2, and E0 does not necessarily ensure maximum energy savings and recovery period shortening. In addition, the maximum annual energy savings (A2 B2 C2 D0 E2 or A2 B2 C2 D2 E2) also do not ensure the maximum amount of net energy savings after recovering the additional costs of construction. Consequently, in terms of making decisions at the design level during renovation, the alternatives A0, $\mathrm{B} 0, \mathrm{C} 0, \mathrm{D} 1$, and E0 are suggested, based on the analysis results, in order to relatively invest smaller construction costs and recover them in the shortest period.

Furthermore, the authors proposed A1, B1, C1, D0, and E2 as alternatives to minimize the net energy costs at maximum during a long-term investment period of 20 years. A2, B2, C2, D0, and E2 are suggested as well to achieve the maximum energy savings despite the huge amount of additional costs. Moreover, A1, B1, C1, D0, and E0 as current legal standards can also represent an efficient alternative in order to guarantee a short time for recovery estimated to 14 years, as well as a high-quantified energy savings after recovering the additional costs, even with investing a relatively small amount for additional costs. 


\section{Conclusions}

As a part of ongoing efforts toward achieving energy savings in existing buildings, several research studies utilizing energy simulation programs have been conducted to select the optimum design standards. However, most of current research in this particular field of study deals only with the degree of energy performance improvements by design variable without considering the economic efficiency. This poses a certain limitation, in that it disallows the building owners to make realistic decisions based on their economic investment conditions.

In this regard, this study sought to present an effective and comprehensive set of guidelines on which items building owners should value depending on their economic investment conditions in decision-making regarding the level of design. This has been achieved through a comprehensive review of the energy savings by design variable on building envelope, energy cost savings, additional construction costs, recovery period, and net energy savings after recovery.

Ultimately, a standard framework was proposed that represents the outcomes of this research. The framework includes key review items for each stage namely, an analysis of design elements for the target building, setting the alternative design variables, performing 3D modeling and energy simulation, as well as conducting the economic analysis and the related insights derived from the findings. The framework is recommended to be utilized in making decisions for design standards or in developing further similar research in future. In this study, the life cycles of finishing were applied equally. Therefore, there is a need for future research to apply the various life åcycles of finishing to the present framework.

Author Contributions: Conceptualization, J.-U.K. and H.K.; Formal analysis, Methodology, and Validation, J.-U.K.; Writing-Original Draft Preparation, J.-U.K. and O.A.H.; Supervision, Project administration, Funding Acquisition, H.K.; Writing-Review \& Editing O.A.H. and J.K.

Funding: This research was funded in part by the Ministry of Land Infrastructure and Transport under Grant 18RTRP-B128346-04-000000 and in part by the National Research Foundation of Korea under Grant 2017R1E1A1A01075266.

Conflicts of Interest: The authors declare no conflict of interest.

\section{References}

1. World Green Building Council (WGBC). Tackling Global Climate Change Meeting Local Priorities: A World Green Building Council Special Report; World Green Building Council: Toronto, ON, Canada, 2010.

2. Sieminski, A. International energy outlook. In Proceedings of the Deloitte Oil and Gas Conference, Houston, TX, USA, 18 November 2014; Energy Information Administration (EIA): Washington, DC, USA, 2014.

3. Mardiana, A.; Riffat, S.B. Building Energy Consumption and Carbon dioxide Emissions: Threat to Climate Change. J. Earth Sci. Clim. Chang. 2015. [CrossRef]

4. Hong, T.; Hastak, M. MEMRRES: Model for evaluating maintenance, repair and rehabilitation strategies in concrete bridge decks. Civ. Eng. Environ. Syst. 2005, 22, 233-248. [CrossRef]

5. Chiang, Y.; Li, J.; Zhou, L.; Wong, F.; Lam, P. Evaluating Sustainable Building-Maintenance Projects: Balancing Economic, Social, and Environmental Impacts in the Case of Hong Kong. J. Constr. Eng. Manag. 2015, 142, 06015003. [CrossRef]

6. Nelson, A.J. Globalization and Global Trends in Green Real Estate Investment; RREEF Research: San Francisco, CA, USA, 2008.

7. Pearce, D. The Social and Economic Value of Construction: The Construction Industry's Contribution to Sustainable Development; New Construction Research and Innovation Strategy Panel: London, UK, 2003.

8. Pearce, D. Is the construction sector sustainable? Definitions and reflections. Build. Res. Inf. 2006, 34, 201-207. [CrossRef]

9. Gökgür, A. Current and Future Use of BIM in Renovation Projects. Master's Thesis, Chalmers University of Technology, Gothenburg, Sweden, 2015.

10. Sheth, A.; Price, A.; Glass, J. BIM and refurbishment of existing healthcare facilities. In Proceedings of the 26th Annual ARCOM Conference, Leeds, UK, 6-8 September 2010; Egbu, C., Ed.; ARCOM: England, UK, 2010. 
11. Volk, R.; Stengel, J.; Schultmann, F. Building information modelling (BIM) for existing buildings-literature review and future needs. Autom. Constr. 2014, 38, 109-127. [CrossRef]

12. Mascio, D.D.; Wang, X. Building Information Modelling (BIM)-Supported Cooperative Design in Sustainable Renovation Projects. In Proceedings of the International Conference on Cooperative Design, Visualization and Engineering, Alcudia, Spain, 22 September 2013; Luo, Y., Ed.; Springer: Berlin/Heidelberg, Germany, 2013.

13. Kim, K.P.; Park, K. BIM feasibility study for housing refurbishment projects in the UK. Organ. Technol. Manag. Constr. 2013, 5, 756-774.

14. Grussing, N.; Liang, Y.L. Knowledge-Based Optimization of Building Maintenance, Repair, and Renovation Activities to Improve Facility Life Cycle Investments. J. Perform. Constr. Facil. 2014, 28, 539-548. [CrossRef]

15. Lee, C.; Hong, T.; Lee, G.; Jeong, J. Life Cycle Cost Analysis on Glass Type of High-Rise Buildings for Increasing Energy Efficiency and Reducing $\mathrm{CO}_{2}$ Emission in Korea. J. Constr. Eng. Manag. 2011, 138, 897-904. [CrossRef]

16. Cho, K.; Yoon, Y. Decision Support Model for Determining Cost-Effective Renovation Time. J. Constr. Eng. Manag. 2015, 32, 04015051. [CrossRef]

17. Kim, H.; Kyle, A. Energy Modeling System Using Building Information Modeling Open Standards. J. Comput. Civ. Eng. 2013, 27, 203-211. [CrossRef]

18. Eleftheriadis, S.; Mumovic, D.; Greening, P. Life cycle energy efficiency in building structures: A review of current developments and future outlooks based on BIM capabilities. Renew. Sustain. Energy Rev. 2016, 67, 811-825. [CrossRef]

19. Kim, H.; Shen, Z.; Kim, I.; Kim, K.; Stumpf, A.; Yu, J. BIM IFC information mapping to building energy analysis (BEA) model with manually extended material information. J. Autom. Constr. 2016, 68, 183-193. [CrossRef]

20. Juan, Y.K.; Gao, P.; Wang, J. A hybrid decision support system for sustainable office building renovation and energy performance improvement. Energy Build. 2010, 42, 290-297. [CrossRef]

21. Kim, S.H.; Shin, K.J.; Choi, B.E.; Jo, J.H.; Cho, S.; Cho, Y.H. A Study on the Variation of Heating and Cooling Load According to the Use of Horizontal Shading and Venetian Blinds in Office Buildings in Korea. Energies 2015, 8, 1487-1504. [CrossRef]

22. Jung, J.W. A Study on the Remodeling of Deteriorated Office Building for the Energy Saving. Master's Thesis, Inha University, Inchen, Korea, 2014.

23. Gwon, J.H. A Study on the Reasonable Goal Setting for Green Remodeling of Office Building. Master's Thesis, Inha University, Inchen, Korea, 2014.

24. Gaskell, P.R. Maintenance Cycles and Life Expectancies of Building Components and Materials: A Guide to Data and Sources; NBA Construction Consultants: London, UK, 1985.

25. Neely, E.S.; Neathammer, R.D.; Stirn, J.R.; Winkler, R.P. Building Maintenance and Repair Data for Life-Cycle Cost Analyses: Architectural Systems; Construction Engineering Research Lab. (ARMY): Champaign, IL, USA, 1991.

26. Chanter, B.; Swallow, P. Building Maintenance Management; Blackwell Publishing: Oxford, UK, 2015. 